\title{
Mortalidade de Alphitobius diaperinus (Panzer) (Coleoptera: Tenebrionidae) por óleos de nim e citronela
}

\author{
Mortality Alphitobius diaperinus (Panzer) (Coleoptera: \\ Tenebrionidae) by neem and citronella oils
}

\author{
Camila Renata Gonçalves Marques ${ }^{1 *}$; Adriana Yatie Mikami ${ }^{2}$; Aline Pissinati ${ }^{1}$; \\ Leonardo Boiani Piva ${ }^{3}$; Odair José Andrade Pais Santos ${ }^{4}$; Maurício Ursi Ventura ${ }^{5}$
}

\section{Resumo}

Estudou-se o efeito do óleo de nim e óleo essencial de citronela associados ou não sobre Alphitobius diaperinus (Panzer). Foram realizados três bioensaios. Para o primeiro estudo, os tratamentos foram com óleo de nim (1, 3, 5, 7 e 9\%). No segundo teste, os tratamentos foram óleo de citronela $(5,1015$ e 20\%) emulsionados com sabão de coco, além dos tratamentos controle com sabão de coco $(10 \mathrm{~g} / \mathrm{L})$ e somente água. Para o terceiro bioensaio, os tratamentos foram óleo de nim e citronela nas concentrações de 1 e 3\%, associados ou não. O óleo de citronela foi emulsionado com detergente neutro biodegradável. Foram também utilizados os controles com detergente e somente água. Depois de tratados, os insetos foram mantidos em câmara climatizada. As avaliações de mortalidade foram realizadas no primeiro, quinto e décimo dia após as pulverizações. De maneira geral, as maiores mortalidades ocorreram $24 \mathrm{~h}$ após a pulverização. Para o óleo de nim a mortalidade acumulada nos 10 dias de avaliação foi de $59 \%$ na concentração de $9 \%$; e para o óleo de citronela foi de $81 \%$ na concentração de $20 \%$. As maiores mortalidades ocorreram nos tratamentos nos quais os óleos foram aplicados juntos. $\mathrm{O}$ tipo de interação entre os óleos foi aditiva para a mortalidade. Palavras-chave: Azadirachta indica, Cymbopogon sp., produção animal

\begin{abstract}
The effects of neem oil and citronela essential oil, alone or associated on Alphitobius diaperinus (Panzer) were studied. Three bioassays were achieved. For the first study, treatments were neem oil $(1,3,5,7$ and $9 \%$.) and control (water). In the second bioassay, treatments were citronella oil (5, 1015 and 20\%) emulsified with coconut soap and control [coconut soap and water $(10 \mathrm{~g} / \mathrm{L})]$. For the third bioassay, treatments were neem oil and citronella essential oil (1 and 3\%), associated or not. After treatment, the insects were kept in an environmental chamber. Assessments of insect mortality were performed on the first, fifth and tenth day after spraying. In general, the highest mortality occurred 24 hours after spraying. Cumulative mortality was $59 \%$ and $81 \%$ for neem $(9 \%)$ and for citronella oil, respectivelly. the highest mortality occurred when the oils were applied mixed. The type of interaction of the control agents on the mortality was additive.
\end{abstract}

Key words: Azadirachta indica, Cymbopogon sp., livestock

\footnotetext{
${ }^{1}$ Discentes do Curso de Doutorado em Agronomia, Curso de Pós-Graduação em Agronomia, Universidade Estadual de Londrina, UEL, Londrina, PR. E-mail: camilargmarques@yahoo.com.br; alinenati@hotmail.com

${ }^{2} \mathrm{Dr}^{\mathrm{a}}$ em Agronomia-Fitossanidade, UEL, Londrina, PR. E-mail: yatiem@gmail.com

${ }^{3}$ Eng $^{\circ}$ Agr ${ }^{\circ}$, UEL, Londrina, PR. E-mail: leo_agrouel@hotmail.com

${ }^{4}$ Discente do Curso de Mestrado em Agronomia, Curso de Pós Graduação em Agronomia, UEL, Londrina, PR. E-mail: odairjap@ gmail.com

${ }^{5}$ Prof. Dr. do Dept ${ }^{\circ}$ de Agronomia, UEL, Londrina, PR. E-mail: mventura@uel.br

* Autor para correspondência
} 


\section{Introdução}

O cascudinho, Alphitobius diaperinus (Panzer) (Coleoptera: Tenebrionidae), é umas das principais pragas associadas à avicultura de corte (CHERNAKI-LEFFER, 2004). Inicialmente era conhecido como praga secundária de farinhas, rações e grãos armazenados e foi introduzido em sistemas de produção animal através de ração infestada (O’CONNOR, 1987; McALLISTER et al., 1995). As condições dos aviários, como temperatura, abrigo e alimento apropriado favoreceram a permanência e multiplicação desta praga causando sérios prejuízos econômicos ao avicultor (TORCH, 1979; SILVA et al., 2001).

Este inseto pode afetar a saúde e desenvolvimento das aves que o ingerem no lugar da ração balanceada e com isso tem sua conversão alimentar reduzida, podendo ainda provocar hemorragias por causarem ferimentos no trato digestivo das aves e transmitir vírus, fungos, bactérias, platelmintos, protozoários e outros parasitos (AXTELL; ARENDS, 1990; DESPINS et al., 1994; MCALLISTER et al., 1995; CHERNAKILEFFER et al., 2002). O cascudinho pode também levar à morte pintinhos recém eclocidos ao perfurar a pele da base dos pés e se alimentando do exsudato sanguíneo (KUMAR, 1986). É considerado como transportador e disseminador de patógenos causando prejuízos econômicos e sanitários na produção avícola (BATES; HIETT; STER, 2004). No Brasil, vários agente patogênicos foram isolados do cascudinho com grande potencial para comprometer significativamente a produção (CHERNAKI-LEFFER et al., 2002).

O controle do cascudinho é dificultado devido ao seu ciclo de vida curto e comportamento que favorece reinfestações, pois se abriga em fendas, rachaduras, abaixo dos comedouros e abaixo do solo, próximo aos pilares de sustentação dos galpões (CHERNAKI-LEFFER et al., 2002). A maioria das táticas de controle está baseada na utilização de inseticidas químicos de curto período residual, cuja utilização causa redução populacional temporária e é limitada pela presença constante dos animais nos aviário, além da possibilidade de selecionar pragas resistentes e causar intoxicações aos animais e ao homem. Assim, é de grande importância o estudo de métodos alternativos de controle visando reduzir a utilização de inseticidas químicos.

Estudos têm demonstrado a eficiência de óleos vegetais no controle de $A$. diaperinus. (MARCOMIN, et al., 2009). As vantagens destes óleos em relação aos inseticidas químicos sintéticos são a persistência e acumulação reduzida ao meio ambiente, pois são biodegradáveis, a compatibilidade com outros métodos de controle e a baixa toxicidade ao homem e animais (VIEIRA; MAFEZOLI; BIAVATTI, 2007).

Entre os óleos vegetais testados no controle do cascudinho, o óleo de nim proveniente da planta Azadiracthina indica A. Juss, demostrou efeitos de deterrência alimentar, inibidora de crescimento e desenvolvimento de larvas e na mortalidade de adultos de $A$. diaperinus (SZCZEPANIK, 2001; TABASSUM et al., 1998; AZEVEDO, 2008). O óleo essencial de citronela (Cymbopogon wynterianus Jowitt) também apresentou efeito inseticida para outro coleóptera [(Tribolium castaneum (Coleoptera: Tenebrionidae)], neste caso, praga de grãos armazenado (AL-JABR, 2006). A utilização do óleo essencial de citronela no controle de $A$. diaperinus é pouco estudada, porém a associação do citronelal, um componente do óleo essencial de $C$. winterianus, aos inseticidas cipermetrina e clorpirifos vem sendo realizada para o controle de $A$. diaperinus com o objetivo de manejo de resistência da praga aos inseticidas químicos sintéticos devido a combinação de diferentes modos de ação (SILVA et al., 2007).

Este estudo tem por objetivo avaliar o efeito do óleo de nim e do óleo essencial de citronela, associados ou não, na mortalidade de $A$. diaperinus. 


\section{Material e Métodos}

Os experimentos foram realizados com adultos da espécie Alphitobius diaperinus, não sexados e de diferentes idades, coletados em aviário comercial no Município de Londrina, Paraná. Os indivíduos (100) foram separados da cama de frango e acondicionados em placas de Petri ( $9 \mathrm{~cm}$ de diâmetro).

Foram realizados três bioensaios nos quais as soluções foram pulverizadas sobre os insetos com pulverizador acoplado a um compressor aspirador $\left(1,0 \mathrm{kgf} \mathrm{cm}^{-1}\right)$, pulverizando-se $0,4 \mathrm{ml}$ de calda por repetição. Após as aplicações, os insetos foram mantidos em câmara climatizada $\left(25 \pm 1^{\circ} \mathrm{C}\right.$ e fotofase de $12 \mathrm{~h}$ ) e alimentados com ração para aves, autoclavada e fornecida 24 horas após a pulverização para evitar a fermentação. As avaliações de mortalidade acumulada dos insetos foram realizadas no primeiro, quinto e décimo dia após a pulverização dos tratamentos.

\section{Óleo de nim sobre adultos de A. diaperinus}

Os tratamentos foram óleo de nim (NeemAzalT/S, Trifolio-M GmbH, Lahnau, Alemanha) com 10 $\mathrm{g} / \mathrm{L}$ de azadiractina A nas concentrações 1, 3, 5, 7 e $9 \%$ e água como testemunha.

\section{Óleo de citronela sobre adultos de A. diaperinus}

Para este experimento, foram utilizadas caldas com óleo essencial de cintronela ( $C$. winterianus) emulsificado com sabão de coco (Rosatex Produtos Saneantes Ltda, Guarulhos, SP) (10g/L). Os tratamentos foram óleo essencial de citronela nas concentrações 5, 10, 15 e 20\%, e os controles com sabão de coco $(10 \mathrm{~g} / \mathrm{L})$, e água como testemunha. O óleo essencial de citronela foi preparado por destilação de material colhido em Marilândia do Sul - PR.

\section{Associação de óleos de nim e citronela}

Neste experimento, os tratamentos foram óleos de nim e citronela em duas concentrações (1 e 3\%), associados ou não. Para o preparo das caldas, foi utilizado detergente neutro biodegradável (Alpes, Química Alpina S.A., Apucarana, Paraná), como emulsificante, que estava presente em todos os tratamentos contendo citronela. Substituiu-se o sabão de coco do primeiro experimento pelo detergente, em função da facilidade de dosar e aplicar o detergente líquido. A concentração de detergente utilizada nos tratamentos foi equivalente à concentração do óleo utilizado.

\section{Delineamento experimental e análise estatística}

Utilizou-se delineamento experimental inteiramente casualizado com seis repetições para o primeiro e segundo experimentos e sete para o terceiro. Realizou-se análise de variância (ANOVA). Nos dois primeiros testes. Após a ANOVA, as médias foram submetidas ao teste $\mathrm{F}$ e regressão de grau 1 ou $2(\mathrm{p}<0,05)$ para verificar o padrão de mortalidade em função das doses dos óleos de nim e citronela. Para o terceiro experimento, as médias foram comparadas pelo teste de Tukey, a 5\% de probabilidade. Os valores de mortalidade acumulada nos dez dias de avaliação foram corrigidos pela fórmula de Shneider e Orelli (1947) (NAKANO; SILVEIRA NETO; ZUCCHI, 1981).

Os dados também foram submetidos ao método que avalia a interação dos agentes de controle em associação pelo teste qui-quadrado $\left(\mathrm{c}^{2}\right)$ (KOPPENHÖFER et al., 2000).

\section{Resultados e Discussão}

A mortalidade $A$. diaperinus, em função das aplicações de doses crescentes dos óleos de citronela e nim, ajustou-se ao modelo de regressão quadrática para o primeiro e segundo bioensaios.

\section{Óleo de nim na mortalidade de A. diaperinus}

Na primeira avaliação, 14 horas após a aplicação, verificou-se que o óleo de nim, nas concentrações 
de $1,3,5,7$ e $9 \%$ causou mortalidade 14 a $47 \%$ (Fig. 1a). No quinto dia após as pulverizações, as concentrações de nim causaram mortalidade acumulada de15 a 53\%, aumentando apenas $1 \%$ para a menor concentração do óleo de $6 \%$ para a maior (Fig. 1 b). No último dia de avaliação, a mortalidade ocasionada pelos óleos de nim foi de 17 a 59\% aumentando apenas 2\% na menor concentração do óleo e $6 \%$ na maior (Figuras 1 c). Pelo padrão de mortalidade verificado nas três datas avaliadas, percebe-se a similaridade dos dados entre as avaliações (Fig 1a,b,c). Este mesmo efeito foi verificado por Tabassum et al. (1998), segundo os quais a maior mortalidade de $A$. diaperinus ocorreu 24 horas após a pulverização de uma formulação de extrato de nim (RB-a), Entretanto, os autores citados utilizaram nim associado com butóxido de piperonila, como agente sinergista, em diferentes doses.

A mortalidade aumentou conforme o acréscimo da concentração de nim até $7 \%$. Na concentração de $9 \%$ não houve aumento da mortalidade em relação a concentração de 7\%. Pela curva, a concentração de óleo de nim para o máximo de controle do cascudinho $(60,22 \%)$ foi de $8,54 \%$ no $10^{\circ}$ dia após a pulverização (ponto máximo).

A atividade inseticida de óleo de nim sobre o cascudinho foi previamente reportada nas concentrações 1, 5 e $10 \%$ que determinaram mortalidades de 31,6, 73,8 e 87,0\% respectivamente, observando-se uma relação direta de dose e mortalidade (MARCOMINI et al., 2009). Neste estudo anterior, os autores utilizaram outra fonte comercial de nim, mas não houve especificação do teor de azadirachtina. Quando se estudou o efeito do nim sobre $A$. diaperinus em amendoim armazenado verificou-se mortalidade aos 90 e 120 em concentrações de 3 e 4\%; efeito regulador de crescimento (deletério na metamorfose de larvas) e fagodeterrente, protegendo as sementes do dano da praga (AZEVEDO et al., 2010).

Óleo de citronela na mortalidade de A. diaperinus

A mortalidade de $A$. diaperinus na primeira avaliação, 24 horas após a aplicação dos tratamentos, variou de 45 a 74\% em função das doses crescentes dos óleos (Figura 2 a). Na segunda avaliação, quinto dia após as pulverizações, as concentrações do óleo de citronela causaram mortalidade acumulada de 51 a 78\%, aumentando apenas $6 \%$ na menor concentração do óleo e 4\% na maior (Figura 2 b). Na última avaliação, dez dias após as pulverizações a mortalidade acumulada nos tratamentos com óleo de citronela foi de 55 a $81 \%$ respectivamente, aumentando apenas $4 \%$ na menor concentração e $3 \%$ na maior (Figura $2 \mathrm{c}$ ). 
Figura 1. Mortalidade de Alphitobius diaperinus após tratamentos com óleo de neem. a) Número de insetos mortos um dia após a aplicação de óleo de nim nas concentrações $0,1,3,5,7$ e 9\%. Equação significativa a p< 0,01 (Y=$\left.0,75 \mathrm{x}^{2}+11,88 \mathrm{x}+1,33 \mathrm{R}^{2}=0,99\right)$. b) Número de insetos mortos com cinco dias após a aplicação de óleo de nim nas concentrações $0,1,3,5,7$ e 9\%. Equação significativa a $\mathrm{p}<0,01\left(\mathrm{Y}=-0,78 \mathrm{x}^{2}+12,91 \mathrm{x}+1,22 \mathrm{R}^{2}=0,98\right)$. c) Número de insetos mortos com dez dias após a aplicação óleo de nim nas concentrações $0,1,3,5,7$ e $9 \%$. Equação significativa a $\mathrm{p}<0,01\left(\mathrm{Y}=-0,80 \mathrm{x}^{2}+13,69 \mathrm{x}+1,78 \mathrm{R}^{2}=0,98\right)$.

a)

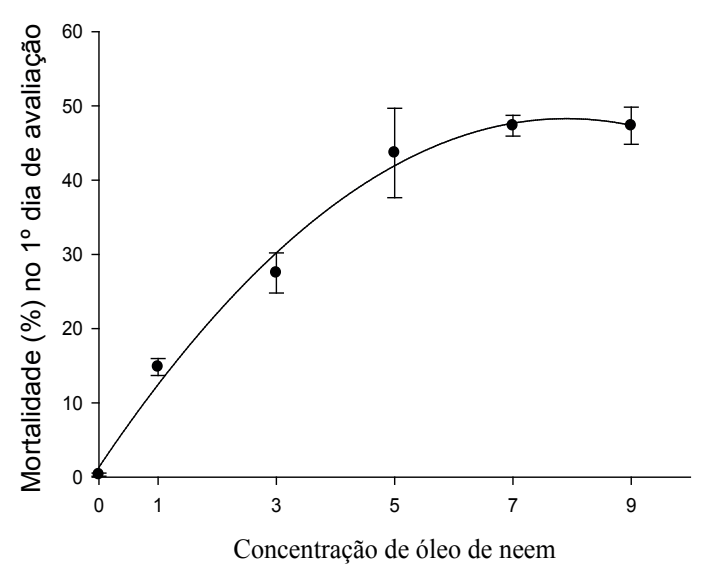

c) b)

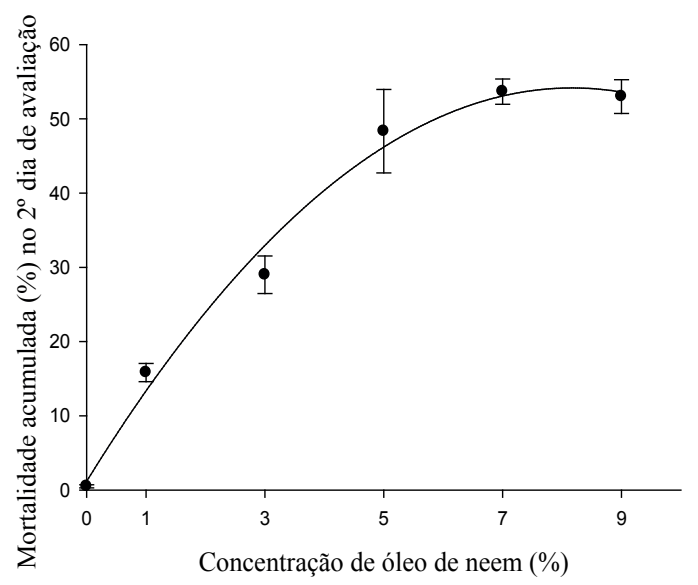

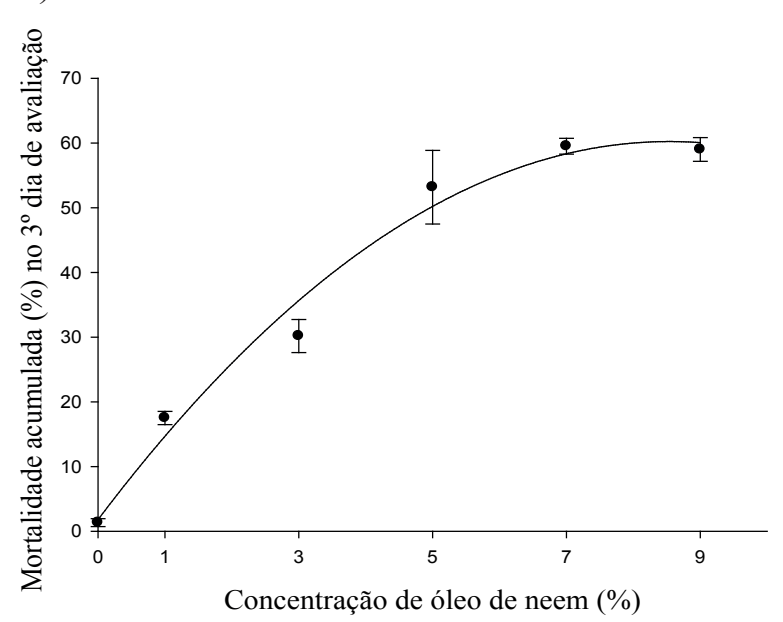

Fonte: Elaborado pelos autores.

Da mesma forma que foi observado no bioensaio com nim, verificou-se padrão similar de respostas nas três datas avaliadas, mostrando que o efeito, aparentemente, é mais pronunciado próximo ao período de aplicação. Não se descarta a possibilidade de outros efeitos do nim e da citronela sobre a praga, inclusive sua progênie, diminuição de alimentação etc. Pela curva, a concentração na qual se obteve a maior mortalidade $(80,1 \%)$ foi de 18,3\% no décimo dia após a pulverização. Em grãos de caupi (Vigna unguiculata L.) armazenado tratado com citronela, verificaram-se as maiores taxas de mortalidade (45\%) sobre Callosobruchus maculatus (F.) (Coleoptera: Bruchidae) também com $24 \mathrm{~h}$ após o contato com do inseto com o óleo (RAJA et al., 2001). 
Figura 2. Mortalidade de Alphitobius diaperinus após tratamentos com óleo de citronela. a) Número de insetos mortos com um dia após a aplicação de óleo de citronela nas concentrações $0,5,10,15$, e $20 \%$. Equação significativa a p< $0,01\left(\mathrm{Y}=-0,18 \mathrm{x}^{2}+7,21 \mathrm{x}+4,19 \mathrm{R}^{2}=0,95\right)$. b) Número de insetos mortos com cinco dias após a aplicação de óleo de citronela nas concentrações $0,5,10,15$, e 20\%. Equação significativa a p< $0,01\left(\mathrm{Y}=-0,21 \mathrm{x}^{2}+7,74 \mathrm{x}+6,00 \mathrm{R}^{2}=0,93\right)$. c) Número de insetos mortos com dez dias após a aplicação de óleo de citronela nas concentrações $0,5,10,15$, e $20 \%$. Equação significativa a $\mathrm{p}<0,01\left(\mathrm{Y}=-0,21 \mathrm{x}^{2}+7,84 \mathrm{x}+8,27 \mathrm{R}^{2}=0,92\right)$.

a)

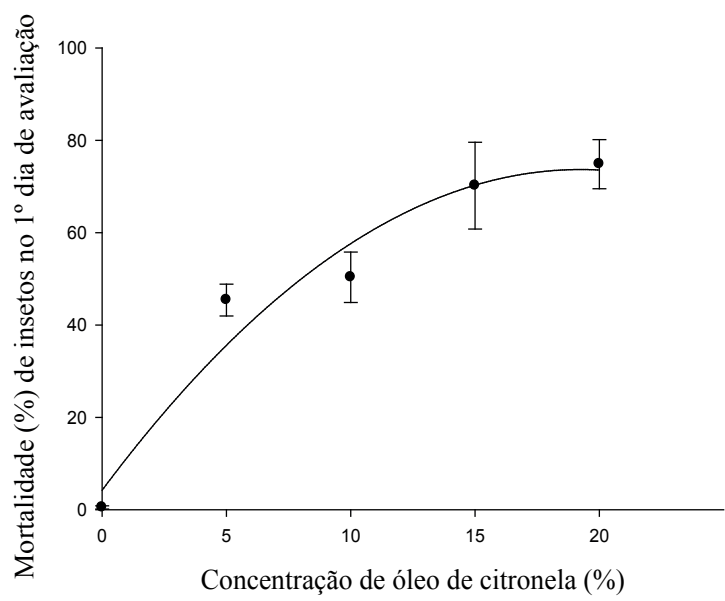

c) b)

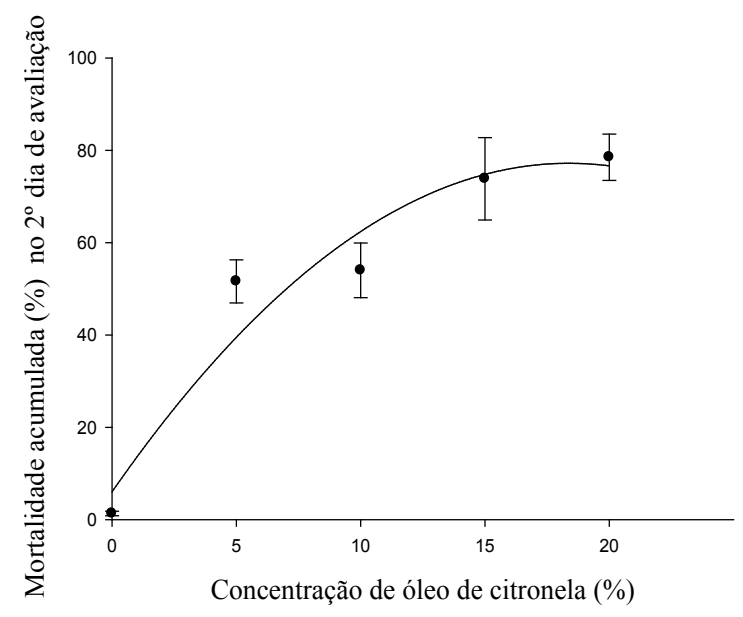

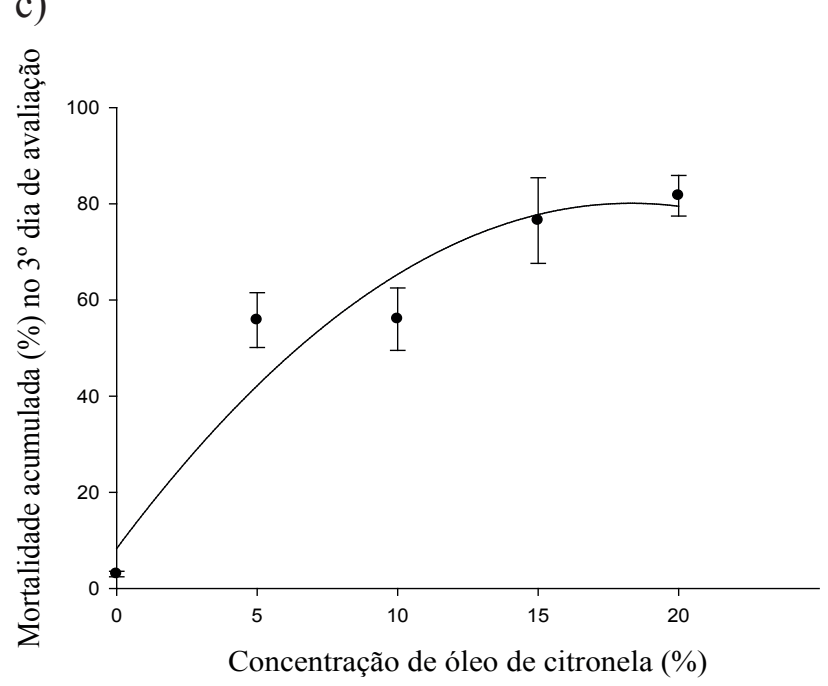

Fonte: Elaborado pelos autores.

A atividade do óleo de citronela para insetos de grãos armazenados também foi reportada para Tribolium castaneum (Tenebrionidae) infestando grãos de trigo (AL-JABR, 2006). Mesmo a partir das menores concentrações $(0,125 ; 0,25 ; 0,5 ; 0 ; 75$ e $1 \%$ ) verificou-se mortalidade, chegando a ser total na concentração de $1 \%$ após duas semanas de exposição.

\section{Associação dos óleos de nim e citronela}

$\mathrm{Na}$ associação de óleo de nim e de citronela, a maior porcentagem de mortalidade $(88,7 \%)$ de $A$. diaperinus ocorreu nos tratamentos com a associação de óleo de neem, citronela e detergente $(3 \%)$ e óleo de citronela e detergente a $3 \%(75$, 
29\%) (Tabela 1). Em todos os tratamentos nos quais detergente) verificou-se efeito aditivo em relação à houve mistura de produtos (óleo de nim, citronela e mortalidade do cascudinho.

Tabela 1. Mortalidade total e corrigida de Alphitobius diaperinus pulverizados com diferentes produtos e tipo de interação entre os mesmos no décimo dia de avaliação.

\begin{tabular}{|c|c|c|c|c|}
\hline \multirow{2}{*}{ Tratamentos } & \multicolumn{3}{|c|}{ Mortalidade $(\%)$} & \multirow{2}{*}{$\begin{array}{c}\text { Interação dos agentes } \\
\text { de controle }\end{array}$} \\
\hline & Total & Corrigida & & \\
\hline Testemunha & $1,43^{1} \pm 0,53$ & - & $\mathrm{f}$ & - \\
\hline $\mathrm{DNB}^{2} 1 \%$ & $4,57 \pm 1,04$ & 3,19 & ef & - \\
\hline DNB 3\% & $22,71 \pm 3,62$ & 21,59 & de & - \\
\hline Óleo de nim 1\% & $17,57 \pm 2,19$ & 16,38 & def & - \\
\hline Óleo de nim 3\% & $45,14 \pm 3,43$ & 44,35 & $\mathrm{bc}$ & - \\
\hline Óleo de nim 1\% + DNB 1\% & $25,86 \pm 3,18$ & 24,78 & $\mathrm{~cd}$ & Aditivo \\
\hline Óleo de nim 3\% + DNB 3\% & $51,43 \pm 3,09$ & 50,72 & $\mathrm{~b}$ & Aditivo \\
\hline Óleo de citronela $1 \%$ + DNB $1 \%$ & $43,29 \pm 6,08$ & 42,46 & $\mathrm{bc}$ & Aditivo \\
\hline Óleo de citronela 3\% + DNB 3\% & $75,29 \pm 6,96$ & 74,93 & $\mathrm{a}$ & Aditivo \\
\hline Óleo de nim $1 \%+$ óleo de citronela $1 \%+$ DNB $1 \%$ & $49,71 \pm 2,60$ & 48,99 & $\mathrm{~b}$ & Aditivo \\
\hline Óleo de nim 3\% + óleo de citronela 3\% + DNB 3\% & $88,86 \pm 7,21$ & 88,70 & $\mathrm{a}$ & Aditivo \\
\hline
\end{tabular}

${ }^{1}$ Médias seguidas de mesma letra na coluna não diferem entre si pelo teste de Tukey p<0,0 5\%.CV: 29,46\%.

${ }^{2}$ Detergente neutro biodegradável.

Fonte: Elaborado pelos autores.

A concentração de detergente a $1 \%$ apresentou desempenho similar à testemunha, porém em concentração de $3 \%$, provocou mortalidade sobre os insetos. O tratamento com óleo de citronela com DNB acarretou mortalidade superior aos tratamentos com nim, sozinho ou mistura com DNB. O óleo de nim também apresentou efeito aditivo na mortalidade de A. diaperinus em outros estudos, quando associado ao fungo entomopatogênico Beauveria bassiana $\left(1 \times 10^{8}\right.$ conidios $\left.\mathrm{mL}-1\right)$ na concentração de $1 \%$. O efeito não-aditivo sinérgico ocorreu com o aumento da concentração do óleo de nim para 2 e 3 \%.(SANTORO et al., 2009). Esses resultados demonstram que tanto no caso da citronela como do fungo, mecanismos independentes estão envolvidos na mortalidade do inseto, não havendo potenciação do efeito pela mistura com o nim. Tentativas do uso de derivados de citronela também foram realizados associando inseticida comercial contendo cipermetrina, clorpirifós e citronelal (CCC) ao fungo entomopatogênico B. bassiana. Também neste caso, a interação dos agentes foi apenas aditiva para larvas e adultos (ALEXANDRE et al., 2008).

$\mathrm{O}$ efeito inseticida de detergentes sobre o cascudinho também tem sido freqüentemente reportado para pragas de tamanho reduzido, como a mosca-branca (BUTLER JÚNIOR et al., 1993), ácaros, pulgões, cochonilhas etc, mas eventualmente o efeito foi observado também sobre insetos maiores como o besouro japonês Popillia japonica Newman (CRANSHAW, 2010), corroborando os resultados verificados neste estudo.

O cascudinho normalmente se localiza na cama do aviário, concentrando-se nos locais com os comedouros e nas áreas chamadas de "alojamento" (onde são agrupadas no início do desenvolvimento) (UEMURA et al., 2008). Apesar das concentrações relativamente elevadas para conseguir mortalide como reportados neste trabalho, eventualmente poder-se-ia estudar o uso destes óleos nas áreas com concentração de insetos, principalmente, se associados com outros métodos de controle. 


\section{Conclusões}

Tanto o óleo de nim quanto a citronela determinaram mortalidade em adultos do cascudinho.

A mortalidade foi pronunciada com $24 \mathrm{~h}$ após a aplicação.

O tipo de interação resultante da associação dos óleos na mortalidade foi aditiva.

\section{Referências}

ALEXANDRE, T. M.; NEVES, P. M. O. J.; SANTORO, P. H.; ALVES, L. F. A. Controle associado de Alphitobius diaperinus com o fungo entomopatogênico Beauveria bassiana e inseticidas químicos. Arquivos Instituto Biológico, São Paulo, v. 75, n. 4, p. 481-489, out./dez. 2008.

AL-JABR, A. M. Toxicity and repellency of seven plant essential oils to Oryzaephilus surinamensis (Coleoptera: Silvanidae) and Tribolium castaneum (Coleoptera: Tenebrioidae). Scientific Journal of King Faisal University (Basic and Applied Sciences), Al-Ahssa, Saudi Arabia, v. 7, n. 1, p. 49-60, 2006.

AXTELL, R. C.; ARENDS, J. J. Ecology and management of arthropod pest of poultry. Annual Review of Entomology, North Carolina State University, Raleigh, v. 35, n. 1, p. 101-126, 1990.

AZEVEDO, A. I. B. Bioatividade do óleo de nim sobre Tribolium Castaneum e Alphitobius diaperinus (Coleoptera: Tenebrionidae) em sementes de amendoim armazenado. 2008. Dissertação (Mestrado em Engenharia Agrícola) - Universidade Federal de Campina Grande, Campina Grande.

AZEVEDO, A. I. B.; LIRA, A. S.; CUNHA, L. C.; ALMEIDA, F. A. C.; ALMEIDA, R. P. Bioatividade do óleo de nim sobre Alphitobius diaperinus (Coleoptera: Tenebrionidae) em sementes de amendoim. Revista Brasileira de Engenharia Agrícola e Ambiental, Campina Grande, v. 14, n. 3, p. 309-313, 2010.

BATES, C; HIETT, K. L.; STER, N. J. Relationship of Campylobacter isolated from poultry and from darkling beetles in New Zealand. Avian Diseases, Washington, v. 48, n. 3, p. 138-147, 2004.

BUTLER JÚNIOR, G. D.; HENNEVERRY, T. J.; STANSLY, P. A.; SCHULSTER, D. J. Insecticidal effects of selected soaps, oils and detergents on the sweetpotato shytefly (Homoptera: Aleyrodidae). Florida
Entomologist, Florida, v. 76, n. 1, p. 161-67, 1993.

CHERNAKI-LEFFER, A. M. Dinâmica populacional, estimativa da resistência a inseticidas e suscetibilidade do cascudinho Alphitobius diaperinus (Panzer, 1797) (Coleoptera: Tenebrionidae) a inseticidas reguladores de crescimento e a fungos entomopatogênicos. 2004. Tese (Doutorado em Ciências Biológicas) - Universidade Federal do Paraná, Curitiba.

CHERNAKI-LEFFER, A. M.; BIESDORF, S. M.; ALMEIDA, L. M.; LEFFER, E. V. B.; VIGNE, F. Isolamento de enterobactérias em Alphitobius diaperinus e na cama de aviários no oeste do estado do Paraná, Brasil. Revista Brasileira de Ciência Avícola, Campinas, v. 4, n. 3, p. 243-247, set./dez. 2002.

CRANSHAW, W. S. Insect control: soaps and detergents. fact sheet $n^{\circ}$. 5547. Insect series. Home and garden. Colorado State University. Extension service. 2010, 2 p.

DESPINS, J. L.; AXTELL, R. C; RIVES, D. V.; GUY, J. S.; FICKEN, M. D. Transmission of enteric pathogens of turkeys by darkling beetle larva (Alphitobius diaperinus). Journal of Applied Poultry Research, North Carolina, v. 3, n. 1, p. 61-65, 1994.

KOPPENHÖFER, A. M.; BROWN, I.; GAUGLER, R.; GREWAL, P. S.; KAYA, H. K.; KLEIN, M. G. Synergism of entomopathogenic nematodes and imidacloprid against white grubs: greenhouse and field evaluation. Biological Control, Ohio, v. 19, n. 3, p. 245-251, 2000.

KUMAR, P. Flesh eating behaviour of Alphitobius diaperinus Panz. (Tenebrionidae: Coleoptera). Indian Journal of Entomology, Indian, v. 48, p. 113-115, 1986.

MARCOMINI, A. M.; ALVES, L. F. A.; BONINI, A. K.; MERTZ, N. R.; SANTOS, J. C. Atividade inseticida de extratos vegetais e do óleo de nim sobre adultos de Alphitobius Diaperinus Panzer (Coleoptera, Tenebrionidae). Arquivos do Instituto Biológico, São Paulo, v. 76, n. 3, p. 409-416, jul./set. 2009.

MCALLISTER, J. C.; STEELMAN, C. D.; NEWBERRRY, L. A.; SKEELES, J. K. Isolation of infectious bursal disease virus from the lesser mealworm, Alphitobius diaperinus (Panzer). Poultry Science, Savoy, v. 74, n. 1, p. 45-49, 1995.

NAKANO, O.; SILVEIRA NETO, S.; ZUCCHI, R. A. Entomologia econômica. São Paulo: Livroceres, 1981. $314 \mathrm{p}$.

O’CONNOR, J. P. Alphitobius diaperinus (Panzer) (Col.: Tenebrionidae) damaging polystyrene insulation in irish piggery. Entomologist's Monthly Magazine, United States, v. 123, p. 1472-1475, 1987.

RAJA, N.; ALBERT, S.; IGNACIMUTHU, S.; DORN, 
S. Effect of plant volatile oils in protecting stored cowpea Vigna unguiculata (L.) Walpers against Callosobruchus maculatus (F.) (Coleoptera: Bruchidae) infestation. Journal of Stored Products Research, Indian, v. 37, n. 2, p. 127-132, abr. 2001

SANTORO, P. H.; NEVES, P. M. O. J.; CAVAGUCHI, S. A.; CONSTANSKI, K.; AMARO, J. T.; ALVES, L. F. A.; GOMES. B. B. Controle associado de Alphitobius diaperinus e efeito de microrganismos eficazes no desenvolvimento de Beauveria bassiana. Revista Brasileira de Agroecologia, Bahia, v. 4, n. 2, p. 164-168, 2009.

SILVA, G. S.; MICHELS, M. G.; TOMA, S. B.; TERRA, F. E.; SOARES, V. E.; COSTA, A. J. Effectiveness of the compound chlorpyrifos + cypermethrin+citronellal against Alphitobius diaperinus. laboratory analysis and residue determination in carcasses. Brazilian Journal of Poultry Science, Campinas, v. 9, n. 3, p. 157-160, jul./ set. 2007.

SILVA, G. S.; VERONEZ, V. A.; OLIVEIRA, G. P.; BORGES, F. A.; SILVA, H. C.; MEIRELES, M. V. Avaliação de métodos de amostragem de "cascudinhos" Alphitobius diaperinus (Panzer) (Coleoptera: Tenebrionidae) em cama de frangos de corte. Semina: Ciências Agrárias, Londrina, v. 22, n. 1, p. 73-76, jan./ jun. 2001.
SZCZEPANIK, M. Studies on the biological activity of azadirachtin lesser mealworm, Alphitobius diaperinus Panzer. In: KONOPINSKA, D. (Ed.). Arthropods chemical, physiological and environmental aspects. Poland: University of Wroclaw, 2001. p. 228-233.

TABASSUM, R.; NAQVI, S. N. H.; JAHAN, M.; NURULAIN, S. M. Determination of the toxicities of fenpropathrin (Pyrethroid) and nim formulation (RB$\mathrm{a}+\mathrm{PBO}+\mathrm{Tx}-100)$ against Alphitobius diaperinus adults and their effects on transaminases. Turkish Journal of Zoology, Turkey, v. 22, n. 4, p. 319-322, 1998.

TORCH, J. M. A new pest of rearing buildings (Alphitobius diaperinus in pigstyes, Brittany). Phytoma, France, v. 308, p. 31-33, 1979.

UEMURA, D. H.; ALVES, L. F. A.; OPAZO, M. A. U.; ALEXANDRE, T. M.; OliVEIRA, D. G. P.; VENTURA, M. U. Distribuição e dinâmica populacional do cascudinho Alphitobius diaperinus (Coleoptera: Tenebrionidae) em aviários de frango de corte. Arquivos do Instituto Biológico, São Paulo, v. 75, n. 4, p. 429-435, 2008.

VIEIRA, P. C.; MAFEZOLI, J.; BIAVATTI, M. W. Inseticidas de origem vegetal. In: FERREIRA, J. T. B.; CORREAA, A. G.; VIEIRA, P. C. Produtos naturais no controle de insetos. São Carlos: Universidade Federal de São Carlos, 2007. 150 p. 
